\title{
A ESTUTURAÇÃO DA REDE URBANA DO NORDESTE PARAENSE A PARTIR DAS INTERAÇÕES ESPACIAIS DAS REDES DE VAREJO
}

\author{
Karina Pimentel dos Santos ${ }^{1}$
}

\begin{abstract}
Resumo: As interações espaciais não se resumem apenas aos fluxos de pessoas, informação, capital e etc., seu processo é caraterizado pela intensa relação entre áreas que estruturam e fortalecem uma rede urbana. Com isto, o presente trabalho vem buscando compreender o destaque das redes de varejo locais dentro da dinâmica de interações espaciais que fortalecem e estruturam a rede urbana do Nordeste Paraense. A pesquisa foi realizada nas cidades de Castanhal, Capanema e Bragança, centros de destaque na região que polarizam outras localidades ao entorno segundo os estudos da REGIC - Regiões de Influência das Cidades (IBGE, 2008), e ao analisar a atuação de algumas redes varejistas que atuam na região (e mantêm sede nessas cidades) foi identificado o papel fundamental das mesmas no processo de estruturação da rede urbana do Nordeste Paraense, já que elas atuam de forma estratégica e hierárquica, estabelecendo fortes interações entre os espaços a partir dos seus fluxos de mercadorias e informações. A presença das redes nos centros urbanos, principalmente de Castanhal, Capanema e Bragança, reforçam a centralidade e ajudam a estruturar o comércio, que atende sua população local e suas áreas de influência. Desta maneira, a atuação e articulação desses agentes econômicos, das redes varejistas, compõem a estrutura da rede urbana do Nordeste Paraense, a partir das suas interações e fluxos que conectam cidade.
\end{abstract}

Palavras-chave: Rede Urbana; Interações espaciais; Redes Varejistas.

Abstract: Spatial interactions are not just about the flows of people, information, capital, etc., their process is characterized by the intense relationship between areas that structure and strengthen an urban network. With this, the present work has been seeking to understand the highlight of local retail chains within the dynamics of spatial interactions that strengthen and structure the urban network of Northeast Paraense. The research was conducted in the cities of Castanhal, Capanema and Bragança, prominent centers in the region that polarize other locations around them according to the studies of REGIC - Regions of Influence of Cities (IBGE, 2008), and analyzing the performance of some retail chains. that operate in the region (and are based in these cities), their fundamental role was identified in the process of structuring the urban network of the Northeast of Paraense, as they act strategically and hierarchically, establishing strong interactions between spaces from their flows. of goods and information. The presence of the networks in urban centers, especially Castanhal, Capanema and Bragança, reinforces the centrality and helps to structure the commerce, which serves its local population and its areas of influence. Thus, the action and articulation of these economic agents, retailers, make up the structure of

\footnotetext{
${ }^{1}$ Mestre em Geografia pela Universidade Federal do Pará (UFP). kasantos1105@ hotmail.com

Estudos Geográficos, Rio Claro, 17(1): 159-174, jan./jun. 2019 (ISSN 1678-698X) http://www.periodicos.rc.biblioteca.unesp.br/index.php/estgeo
} 
A estruturação da rede urbana...

the urban network of Northeast Paraense, from their interactions and flows that connect the city.

Keywords: Urban Network; Space Interactions; Retailers.

\section{INTRODUÇÃO}

As cidades de Castanhal, Capanema e Bragança, localizadas no nordeste do estado do Pará, exercem o papel de centro urbano regional e junto com as localidades do entorno formam o que podemos chamar de Região do Nordeste Paraense, uma denominação não oficializada pelo governo estadual ou federal, mas estabelecida a partir dos dados do estudo Regiões de Influência das Cidades REGIC 2007 (IBGE, 2008), sob da noção de região formada por sua rede de cidades e do reconhecimento de suas centralidades e áreas de influência (RIBEIRO, 2016).

A partir desta articulação, principalmente econômica, se pode falar na existência de uma rede urbana constituída no Nordeste Paraense, que Corrêa (1989) afirma ser um conjunto de centros urbanos funcionalmente articulados, que reflete e reforça as características sociais e econômicas do território, sendo uma dimensão socioespacial da sociedade. Dentro desta estrutura de rede urbana 0 autor supracitado afirma existir pontos fixos onde se realizam trocas, negociações, interações, etc., que são os principais centros urbanos da região, neste caso da zona bragantina os destaques são os centros de Bragança, Capanema e Castanhal.

Estas localidades são centrais porque possuem um comércio de grande importância que abastece e atende suas populações e os municípios vizinhos - tanto em gêneros alimentícios, artigos no varejo e atacado, entre outros serviços -, e também porque possuem uma situação espacial favorável, com vias de acesso a várias cidades e agrovilas; o estudo REGIC 2007 assegura que a oferta de distintos equipamentos e serviços é capaz de dotar uma cidade de centralidade e complementar a identificação dos centros de gestão do território (IBGE, 2008).

As cidades de Castanhal, Capanema e Bragança atualmente exercem uma centralidade na região, como já foi dito anteriormente, e o comércio das redes varejistas contribuem significativamente neste papel, pois muitas pessoas das cidades vizinhas se deslocam em busca dos serviços ofertados por essas lojas, gerando o que Corrêa (2006a) chama de interações espaciais, que segundo ele constitui um amplo e complexo conjunto de deslocamento de pessoas, mercadorias, capital, informação, sobre o espaço geográfico.

O setor que mais se destaca nestas cidades é o comércio, fator herdado da colonização influenciada pela Estrada de Ferro de Bragança-EFB, que tornou estas cidades centros favoráveis ao desenvolvimento do comércio e dos serviços e, posteriormente, já com a malha rodoviária, deu condições para o surgimento/implantação de várias empresas, como é o caso das redes varejistas do Nordeste Paraense que cresceram e se expandiram, ampliando suas lojas e se espalhando de forma estratégica por toda a região. Neste sentido, surge a problemática da pesquisa em questão: de que maneira as redes de varejo atuam para fortalecer e estruturar a rede urbana do Nordeste Paraense? E como questões norteadoras procurou-se investigar: Quais seriam suas implicações para a centralidade das cidades de Castanhal, Capanema e Bragança? Qual a relevância das redes varejistas para a economia local dessas cidades?

Estudos Geográficos, Rio Claro, 17(1): 159-174, jan./jun. 2019 (ISSN 1678-698X) http://www.periodicos.rc.biblioteca.unesp.br/index.php/estgeo 
Os questionamentos levantados são relevantes perante os esclarecimentos de Corrêa (2014) que levanta as características de uma rede urbana que envolve a sociedade que exerce suas transações comerciais e interações espaciais em rede, a partir de uma mínima diferenciação entre os espaços que estão funcionalmente articulados entre si, essa articulação é realizada por diversos objetivos e por agentes distintos. As redes de varejo podem ser classificadas enquanto um dos exemplos de agentes comerciais, seus vetores de interações espaciais são importantes fluxos de informações e mercadorias que compõem a rede urbana do Nordeste Paraense (RIBEIRO, 2017), compreender esse elemento de fortalecimento regional mais a fundo o destaque que as redes varejistas possuem torna-se necessário para a região em questão, pouco explorada nessa perspectiva.

Portanto, a pesquisa tem como objetivo geral compreender o destaque das redes de varejo locais dentro da dinâmica de interações espaciais que fortalecem e estruturam a rede urbana do Nordeste Paraense. Como objetivos específicos procura-se verificar o papel das redes de varejo para a centralidade das cidades de Castanhal, Capanema e Bragança; analisar a relevância das redes varejistas para a economia dessas cidades.

O presente trabalho foi construído com base em três eixos fundamentais: construção do referencial teórico, análise documental e trabalho de campo. $\mathrm{Na}$ primeira parte foi realizada a pesquisa sobre os principais conceitos que norteiam a pesquisa: rede urbana, interações espaciais e sobre o varejo/comércio varejista, que norteiam a discussão para o trabalho. A segunda parte da metodologia foi realizada em duas fases: o levantamento histórico sobre o processo de povoamento da área do nordeste paraense - que iniciou a partir da construção da EFB - e sobre a análise da importância das cidades de Bragança, Capanema e Castanhal; e o levantamento documental da análise da avaliação da REGIC 2007 (IBGE, 2008) e da Divisão Urbano Regional (IBGE, 2013), que deu o suporte sobre os dados necessários à compreensão da dinâmica das cidades estudadas, como a classificação dos centros urbanos e suas regiões de influência. Na terceira parte, do trabalho de campo, foi realizada a análise do centro urbano de Castanhal, Capanema e Bragança para a identificação dos principais grupos varejistas originários da região (as redes selecionadas foram os grupos Marilar, Jomóveis, Radisco e Eletromóveis) que se constituem em redes pelo Nordeste Paraense; e entrevista com as gerências das lojas para compreender suas dinâmicas de atuação.

O trabalho está organizado em três partes: o primeiro tópico vem discutindo os conceitos de rede urbana e interações espaciais, como estas estruturam uma rede urbana, além de analisar o papel do comércio varejista para as centralidades das cidades. No segundo aborda-se sobre o processo histórico de construção da região do Nordeste Paraense. E para finalizar, o terceiro tópico aborda a dinâmica das redes varejistas, Marilar, Jomóveis, Radisco e Eletromóveis, e a sua contribuição para fortalecimento da rede urbana do Nordeste Paraense.

\section{AS INTERAÇÕES ESPACIAIS NA REDE URBANA}

Tratar de rede urbana é realizar a análise sobre a articulação entre as cidades e identificar as distintas relações existentes entre seus centros urbanos. Corrêa (1989) conceitua a rede urbana como um conjunto de centros funcionalmente articulados, que reflete e recria as características sociais e econômicas do território, sendo uma dimensão socioespacial da sociedade. $O$ autor supracitado enfatiza que a rede urbana é um reflexo dos efeitos acumulados da prática de diferentes agentes

Estudos Geográficos, Rio Claro, 17(1): 159-174, jan./jun. 2019 (ISSN 1678-698X) http://www.periodicos.rc.biblioteca.unesp.br/index.php/estgeo 
sociais, como grandes corporações que introduzem atividades que geram diferenciações entre os centros urbanos, então, o mesmo afirma ser necessário compreender a lógica de implantação das atividades no complexo mosaico de centros e hinterlândias em seus diferentes papeis e pesos, e desvendar as motivações dos diversos agentes sociais. A rede urbana é um sistema que apresenta funções, processos e estrutura em suas diferentes formas, assim como afirma Corrêa (1989, p. 70-71):

A rede urbana pode ser considerada como uma forma espacial através da qual as funções espaciais se realizam. Estas funções comercialização de produtos rurais, vendas varejistas, prestação de serviços diversos etc.- reportam-se aos processos sociais, dos quais a criação, apropriação e circulação do valor excedente constitui-se no mais importante, ganhando características específicas na estrutura capitalista.

Dessa forma, pode-se entender que a rede urbana é um sistema complexo que deriva das ações de diferentes agentes sociais, e se constitui a partir de estruturas espaciais envolvendo diferentes centros urbanos e atividades diferenciadas. Corrêa (1989) pontua três condições mínimas para a constituição de uma rede urbana: primeiro deve haver economia de mercado com uma produção que é negociada por outra que não é produzida local ou regionalmente; segundo, deve haver pontos fixos no território onde os negócios acima referidos são realizados; e a terceira condição é que deve existir uma mínima articulação entre os núcleos anteriormente referidos. O conjunto destes três fatores é suficiente para constituir uma rede urbana, porém cada uma vai ser distinta de outra por ter sua periodização histórica de construção diferenciada, isto porque os processos que definem uma rede urbana não atuam por igual em qualquer espaço, e este processo de periodização espacial evidencia as ocasiões e os momentos que caracterizam o processo de construção da rede urbana e também das formas criadas em cada momento (CORRÊA, 2006b).

Dentro de uma rede urbana existe a diferença/classificação funcional entre as cidades, pois estas se destacam a partir de algumas atividades/serviços. Corrêa (1989) afirma que este processo de diferenciação se constitui em um reflexo da/e uma condição para a divisão territorial do trabalho, além disso, o capitalismo acentua o processo de diferenciação das cidades, onde há um mercado consumidor e uma industrialização que leva à expansão da oferta de produtos industriais e de serviços, porém esta oferta se verifica de modo espacialmente desigual.

A diferenciação, tanto funcional como de localização, entre os conjuntos de centros urbanos funcionalmente articulados fortalece e estabelece a hierarquia urbana, de acordo com o papel característico que as cidades apresentam. Este padrão hierárquico é cumulativo, ou seja, à medida que se eleva o nível de hierarquia se verifica um acúmulo de funções centrais e mais destaque a cidade possui no âmbito da rede urbana, ou seja, quanto

[...] maior o nível hierárquico de uma localidade central, maior o número e funções centrais, sua população urbana, sua região de influência e o total da população servida. Inversamente, maior o número de centros do mesmo nível e mais distanciados estão entre si. (CORRÊA,1989, p. 28-30).

Estudos Geográficos, Rio Claro, 17(1): 159-174, jan./jun. $2019 \quad$ (ISSN 1678-698X) http://www.periodicos.rc.biblioteca.unesp.br/index.php/estgeo 
A circulação é necessária dentro da rede urbana, pois complementa a lógica capitalista que envolve produção e consumo, esses processos ocorrem de forma diversificada entre as cidades (como já foi tratado) em que cada uma tem o papel de difusor do desenvolvimento do modo de produção capitalista e a circulação é que fundamenta a lógica em rede, integrando os centros urbanos e interligando-os.

Dentro desta rede urbana não circulam apenas pessoas, mas também capital, informação, produção etc. Este processo de articulação das cidades se insere no contexto das interações espaciais, que são mais que relações entre diferentes espaços, constituem interligações entre eles que podem se refletir em um amplo e complexo conjunto de deslocamentos de diferentes origens e diversos propósitos, sobre o assunto Corrêa (2006a, p. 280) afirma que:

As interações espaciais devem ser vistas como parte integrante da existência (e reprodução) e do processo de transformação social e não puros e simples deslocamentos de pessoas, mercadorias, capital e informação no espaço. No que se refere à existência e reprodução social, as interações refletem as diferenças de lugares face às necessidades historicamente identificadas. No que concerne às transformações, as interações espaciais caracterizam-se, preponderantemente, por uma assimetria, isto é, por relações que tendem a favorecer um lugar em detrimento de outro, ampliando as diferenças já existentes, isto é, transformando os lugares.

Entende-se, desta forma, que se for analisar apenas os deslocamentos de pessoas, mercadorias, capital e informação pelo espaço não será possível compreender as interações espaciais, pois esses pontos são, na verdade, o reflexo deste fator que está imbricado na existência e reprodução da sociedade, isto porque representam a diferença, historicamente construída, dos lugares; desta maneira, as interações espaciais acabam por reforçar essas diferenças e transformar os lugares. Estas transformações representam não apenas as desigualdades entre as localidades, mas o fato de que os espaços, a partir das interações espaciais, passam a se relacionarem de forma intensa e se tornam imbricados. São cidades tão conectadas que aparentam ser uma só construindo uma rede de relações. Neste sentido, Corrêa (2006a) afirma que mesmo de forma desigual as transformações verificam-se em toda parte e geram uma economia crescentemente integrada em escala mundial, constituída por nós e áreas articuladas entre si por poderosas ligações, que se refleti na dinâmica da rede urbana.

Entretanto, a interação não ocorre apenas por simples diferenciação espacial, Ullman (1980) afirma que para poder existir relações entre dois espaços deve haver a demanda de uma e o suprimento na outra, desta forma a interação pode ocorrer entre duas áreas aparentemente semelhantes, desde que haja complementariedade específica, tornando possível o estabelecimento das rotas de transportes, pois se houver entraves logísticos entre os espaços que torne os deslocamentos/relações inacessíveis a interação não ocorrerá, restando à população procurar outro centro em busca de abastecimento e aos agentes capitalistas outra saída para suprir suas necessidades de mercado.

O processo de interação espacial não ocorre apenas por conta dos espaços diferenciados, já que existem vários lugares distintos que não possuem relações. A necessidade de se conectarem parte da ideia de que em certa área deve haver a demanda de uma e o suprimento na outra. Um fator também complementar para a existência deste processo, em termos de custo e tempo, é a distância, que se for

Estudos Geográficos, Rio Claro, 17(1): 159-174, jan./jun. 2019 (ISSN 1678-698X) http://www.periodicos.rc.biblioteca.unesp.br/index.php/estgeo 
grande e difícil demais se torna inviável manter relações e conexões, restando substituir as necessidades e demandas por outras alternativas. A partir desta ideia Ullman (1980) afirma que o fator intervencionista resulta na substituição de área e a distância resulta na substituição de produtos, e destaca que as rotas comerciais hoje em dia são muito mais avançadas do que nos tempos passados e que as interações espaciais fazem parte do aumento e melhoria dos fluxos de bens e pessoas, estruturando as áreas em questão.

Compreende-se que a interação espacial faz parte da (re)produção dos espaços a partir das relações entre os agentes de diversas localidades e do modo como a sociedade e as empresas interagem conectando cidades e regiões. Esses agentes transformam os lugares de acordo com suas necessidades expressas por deslocamentos dinâmicos.

Um exemplo de atividade que realiza e estrutura os fluxos pelo espaço é o varejo, setor fundamental nas relações de troca para o comércio, que realiza a mediação entre a fábrica e o consumidor final, com extrema importância dentro dos centros urbanos. Esta atividade já acompanha o desenvolvimento das cidades desde os primórdios, sendo que Atenas, Alexandria e Roma foram grandes áreas comerciais. Las Casas \& Barbosa (2007) comentam que a evolução do varejo em geral está diretamente relacionada ao cenário em que se assenta a infraestrutura das cidades, a partir disto se pode pressupor o destaque da atividade varejista para os centros urbanos.

O varejo está intimamente relacionado à imagem das lojas/empresas, que se organizam de diversas formas, como, por exemplo, em uma única sede, em franquias ou em redes. Esta última forma é o que chamamos de redes varejistas, agentes comerciais que se expandem dentro das cidades e por outros centros urbanos, são caracterizadas pela articulação em rede que se materializa em fluxos de mercadorias e informações. As redes varejistas se organizam a partir de uma loja sede (onde se apresenta o centro de gestão da empresa, a gerência principal) e outras lojas filiais que se espalham de forma estratégica, de acordo com a logística de plano da empresa.

Esta lógica é a base para entender o modo de agir sobre o espaço a partir de um ponto de vista do comércio varejista que impulsionam o fluxo de pessoas, mercadorias, informação etc., dando centralidade à determinadas cidades e fazendo parte da estruturação da rede urbana. $A$ análise em questão será realizada mais a frente, discutindo as características das redes varejistas, selecionadas para 0 estudo, que atuam na região do Nordeste Paraense, consolidando e fortalecendo sua rede urbana. No próximo tópico será discutido o processo de formação desta região e os seus centros de destaque.

\section{A REGIÃO DO NORDESTE PARAENSE}

O marco inicial da ocupação na Amazônia começou com o projeto da Coroa Ibérica para criação de fortes em novos núcleos de povoamento com a intenção de proteger a região de invasões europeias, a primeira sede fundada foi Belém, em 1616, devido a sua posição estratégica, no encontro da foz do Rio Guamá com a Baia do Guajará. Nesta leva do projeto de controle territorial outros núcleos foram criados, como Cametá, Gurupá, Salinas e Bragança, esta, que já tinha uma origem remota como Sousa de Caeté desde 1622, foi um ponto estratégico facilitando o contado de Belém com São Luiz, para fins de contatos políticos e para abastecimento. Todo este processo inicial de ocupação para proteger o território Estudos Geográficos, Rio Claro, 17(1): 159-174, jan./jun. 2019 (ISSN 1678-698X) http://www.periodicos.rc.biblioteca.unesp.br/index.php/estgeo 
amazônico ficou sobre responsabilidade das ordens religiosas, em especial dos Jesuítas que tiveram em seus domínios um maior número de indígenas. A partir do século XVIII, vários outros núcleos foram criados com o incentivo da política pombalina, em 1750, em que as ordens religiosas foram expulsas da região e todas estas ocupações foram transformadas em vilas; essa política se apoiava em pelo menos quatro elementos: as fortificações, o povoamento nuclear, a criação de unidades administrativas e o conhecimento geográfico do território (TAVARES, 1992).

Até o século XIX o percurso à Bragança (que estabelecia importantes ligações com São Luiz no Maranhão) pelo mar era caro e perigoso, as embarcações necessitavam constantemente atracar ao litoral para fins de abastecimento e abrigo, este fator fortaleceu a criação de núcleos no litoral paraense, o que consolidou a formação do povoamento na área que hoje é conhecida como a região do Salgado devido a intima ligação dos núcleos com o mar e por conta da economia ser voltada principalmente para a pesca, são eles: Quatipuru, São João de Pirabas, Salinas, Maracanã, Marapanim, Curuçá, São Caetano de Odivelas, Pinheiro e Vigia de Nazaré. (ÉGLER, 1961).

Com a nova situação social, na primeira metade do século XIX, Belém já apresentava um relevante crescimento populacional e adquiria características de centro urbano, porém, sua produção agrícola não estava mais suficiente para manter o abastecimento, e como sua relação com o Maranhão não se fazia de forma satisfatória o estado direcionou a atenção para a área de expansão da cidade, 0 nordeste do estado do Pará; o trecho por terra nesta área era constituída por mata virgem e instigou os governantes a incentivar a criação de colônias agrícolas para fins de abastecimento da capital. Desta forma, visando o intenso processo de colonização e o escoamento da safra surge a necessidade de se estabelecer uma comunicação hábil com esses locais, por isso, o governo cogita a solução de implantar um meio de transporte que alcançasse esta região e contribuísse na ligação efetiva com o Maranhão, surge então a ideia do projeto para implantar uma via férrea, a partir disto inicia-se em junho de 1883 a construção da Estrada de Ferro de Bragança - EFB (ÉGLER, 1961).

Em 1908 a EFB é finalizada depois de um longo período de construção em que houve diversos atropelos e estagnações durante a obra. Desta maneira, as vilas e colônias de produção agrícola ganharam maior dinamismo com a construção desta ferrovia que fomentou ainda mais o surgimento de novas localidades no Nordeste do Pará, fugindo de certa maneira do padrão de povoamento dentrítico ${ }^{2}$ constituído na Amazônia. Esta zona bragantina se firmou então como o celeiro de abastecimento de Belém, com imensas áreas devolutas com base de uma agricultura primitiva (ÉGLER, 1961).

Pode-se, desta forma, perceber a contribuição significativa da dinâmica da EFB para a formação/constituição da região do Nordeste Paraense, fomentando a colonização e o desenvolvimento dos centros urbanos que já existiam e dos que foram formados a partir da fixação da construção.

A dinâmica do Nordeste Paraense torna-se diferente, em que a EFB deixou de ser utilizada e abriu espaço para as rodovias, como: a BR-316 que segue quase o mesmo trajeto da antiga rota da ferrovia, de Belém a Castanhal, esta, servindo

\footnotetext{
${ }^{2} \mathrm{O}$ padrão de povoamento dendrítico é caracterizado pela criação de cidades em pontos estratégicos e excentricamente localizadas juntas/próximas ao mar ou ao curso de um rio, com a intensão de penetração e conquista do território, guardando sua entrada e saída.
}

Estudos Geográficos, Rio Claro, 17(1): 159-174, jan./jun. $2019 \quad$ (ISSN 1678-698X) http://www.periodicos.rc.biblioteca.unesp.br/index.php/estgeo 
como entroncamento rodoviário é o ponto de acesso a outras cidades pelas PA-136 (em direção a Curuçá ao norte, e Inhangapí ao sul) e PA-320 (em direção a lgarapéAçú, São Francisco, Capanema, etc.).

Por isso, a constituição da rede urbana do Nordeste Paraense teve suas bases nos processos históricos e sua dinâmica baseada principalmente nas relações entre os centros urbanos, a partir das interações espaciais que vários agentes/sujeitos realizam. Essas interações ocorrem por diversos fatores e são facilitadas pelas vias de circulação estrategicamente estabelecidas. Nestas condições, a rede urbana da região é organizada em torno dos três centros subregionais: Castanhal, Capanema e Bragança, que, junto às suas áreas de influência, mantêm relações fortalecendo a dinâmica em rede (FIGURA 1), a partir da classificação do estudo da REGIC 2007 (IBGE, 2008), que definiu posição destas cidades dentro da hierarquia regional, demarcando Castanhal como Centro subregional $A$, e as cidades de Capanema e Bragança como Centro sub-regional $B$, junto com suas áreas de influência ${ }^{3}$.

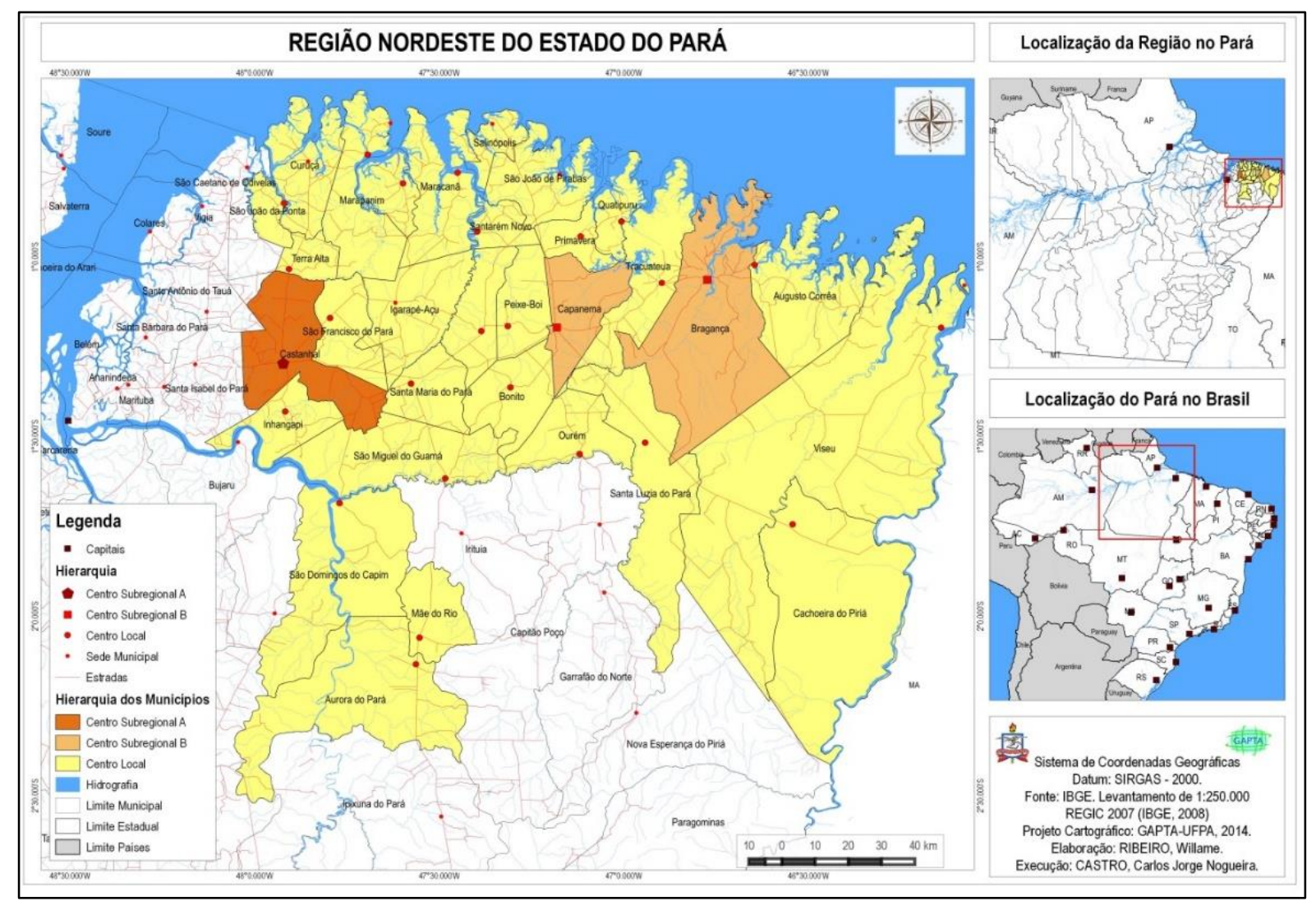

Figura 1 - Região do Nordeste Paraense. Delimitação, municípios componentes e hierarquia urbana (2013).

Fonte: Ribeiro (2017).

\footnotetext{
${ }^{3}$ Áreas de influência de Castanha (Aurora do Pará, Inhangapí, Mão do Rio, Magalhães Barata, Maracanã, Marapanim, Santa Maria do Pará, São Domingos do Capim, São Francisco do Pará, São João da Ponta, São Miguel do Guamá, Terra Alta, Igarapé-Açu, Irituia); Capanema (Bonito, Cachoeira do Piriá, Nova Timboteua, Ourém, Peixe Boi, Primavera, Quatipuru, Santa Luzia do Pará, Santarém Novo, Salinópolis, São João de Pirabas); Bragança (Augusto Corrêa, Tracuateua, Viseu). FONTE: REGIC 2007 (IBGE, 2008) e Divisão Urbano Regional (IBGE, 2013).
}

Estudos Geográficos, Rio Claro, 17(1): 159-174, jan./jun. 2019 (ISSN 1678-698X) http://www.periodicos.rc.biblioteca.unesp.br/index.php/estgeo 


\section{INTERAÇÕES E CENTRALIDADES A PARTIR DAS REDES DE VAREJO: MARILAR, JOMÓVEIS, RADISCO E ELETROMÓVEIS}

O processo de formação de uma rede urbana é composto pela interação entre os diferentes centros urbanos, essas são realizadas por diversos agentes, como as redes varejistas, que são grupos que se espacializam de forma estratégica e estabelecem relações dentro da rede. Desta forma, as interações espaciais são fatores que estão imbricados nas formas de atuação de qualquer rede varejista, pois esses agentes comerciais têm como principal característica sua forma estratégica de espacialização por outros centros urbanos, ou seja, se articulam em rede a partir de diferentes fluxos.

Nestas condições, as redes varejistas que atuam no Nordeste Paraense dispõem de uma facilidade de acesso para manter relações e atuar de forma estratégica dentro da região, esses agentes realizam a interação entre os espaços a partir dos seus fluxos, de mercadorias, capital, informações, etc., compondo a dinâmica regional e efetivando a relação entre as cidades. A atuação em rede além de compor o atual cenário do espaço geográfico realizam o movimento dialético no território, a partir das relações entre os fixos e os fluxos, Pereira \& Kahil $(2006,218)$ comentam que "os diferentes tipos de redes transportam objetos e informações, comunicam dados, compartilham posições políticas e ordens no espaço geográfico, entre diferentes pontos e agentes" conferindo uma pluralidade e particularidade nesse espaço.

A atividade em rede não tem como propósito apenas distribuir, o papel principal é circular dados e informações que são fundamenteis para as atividades de organização espacial que transformam o território "podem ser compreendidas como estruturas fundamentais para o desenvolvimento de novas estratégias de realização e distribuição do processo produtivo, e, dialeticamente, de transformação dos territórios" (PEREIRA \& KAHIL, 2006, p. 22). Como exemplo pode-se verificar a região do Nordeste Paraense que se fortaleceu a partir dos seus nós, dos centros urbanos de Castanhal, Capanema e Bragança e suas áreas de influência, e o comércio é um dos setores de destaque dessas localidades centrais, a partir principalmente das articulação em rede dos agentes varejistas que têm papel importante para o destaque/desenvolvimento das cidades.

Neste sentido, o estudo analisa as principais redes varejistas, empresas oriundas da região e que têm destaque em suas lógicas de espacialização, pois se estruturam em forma de redes, são elas: Marilar, Jomóveis, Radisco e Eletromóveis. Essas lojas são procedentes de grupos familiares que abriram sua primeira loja na cidade em que residiam e a partir do seu crescimento e desenvolvimento foram se expandindo e abriram filiais pelo nordeste do Pará, que são bem reconhecidas e possuem destaque nos centros das cidades onde estão presentes.

Estudos Geográficos, Rio Claro, 17(1): 159-174, jan./jun. $2019 \quad$ (ISSN 1678-698X) http://www.periodicos.rc.biblioteca.unesp.br/index.php/estgeo 
A estruturação da rede urbana...

Quadro 1 - Redes varejistas do Nordeste do Pará. Caracterização geral (2016).

\begin{tabular}{|c|c|c|c|c|c|c|}
\hline \multirow{2}{*}{$\begin{array}{l}\text { REDES DE } \\
\text { VAREJO }\end{array}$} & \multicolumn{6}{|c|}{ PRINCIPAIS CARACTERISTICAS } \\
\hline & Setor do varejo & $\begin{array}{l}\text { Local de } \\
\text { fundação }\end{array}$ & Sede & $\begin{array}{c}\text { Centro de } \\
\text { distribuição }\end{array}$ & $\begin{array}{l}\mathrm{N}^{0} \mathrm{de} \\
\text { lojas }\end{array}$ & $\begin{array}{l}\text { Número de } \\
\text { funcionários }\end{array}$ \\
\hline Marilar & $\begin{array}{c}\text { Móveis e } \\
\text { eletrodomésticos }\end{array}$ & Capanema & Castanhal & Santa Isabel & 19 & 192 \\
\hline Radisco & $\begin{array}{c}\text { Móveis e } \\
\text { eletrodomésticos/ } \\
\text { Loja de } \\
\text { departamentos }\end{array}$ & Capanema & Capanema & Capanema & 10 & 270 \\
\hline Jomóveis & $\begin{array}{c}\text { Móveis e } \\
\text { eletrodomésticos }\end{array}$ & Bragança & Castanhal & Castanhal & 9 & 190 \\
\hline Eletromóveis & $\begin{array}{l}\text { Móveis e } \\
\text { eletrodomésticos } \\
\text { / Loja de } \\
\text { departamentos / } \\
\text { Móveis e } \\
\text { decoração }\end{array}$ & Capanema & Capanema & $\begin{array}{l}\text { Capanema } \\
\text { Castanhal } \\
\text { Belém }\end{array}$ & 3 & 360 \\
\hline
\end{tabular}

Fonte: Trabalho de campo, 2016.

Além dessas ações de logística as redes varejistas estabelecem estratégias de atuação que as caracterizam como agentes econômicos com forte atuação espacial, pois as redes de varejo possuem padrões de espacialização, como Marilar, Jomóveis e Radisco que apresentam um modelo mais expansionista, como pode ser verificado no Quadro 1, com a intenção de priorizar o acesso às mercadorias para várias cidades. Neste sentindo, esses grupos analisam os centros urbanos antes de se estabelecerem, verificando se há um fluxo de pessoas necessário, uma estrutura de serviços que os atendam, um mercado ativo, uma dinâmica que se adeque ao padrão da empresa, etc. Esses critérios são norteadores para a forma de expansão desses grupos, o que os caracteriza como agentes capitalistas estratégicos.

O grupo Eletromóveis possui um modelo mais diferenciado, pois trabalha com apenas três sedes, porém sua estratégia de espacialização é bem mais rebuscada no sentido de serem lojas de grande porte, mas situadas apenas em cidades polos, por isso o grupo só atua em Capanema, Castanhal e Belém (QUADRO 1), que apresentam uma área de influência de destaque; a intenção do grupo não é abrir novas filiais e sim melhorar sua estrutura, tecnologia e atendimento, esse planejamento caracteriza a rede como um agente estratégico de nível diferenciado, pois atua de acordo com o melhor espaço, disponibiliza mercadorias de acordo com o poder aquisitivo da população e estabelece o seu funcionamento de crédito de acordo com o padrão dos seus clientes em cada cidade. A forma de espacialização das redes varejistas do Nordeste Paraense está exposta na Figura 2, em que pode-se observar, materializado no espaço, essas lógicas de atuação.

A partir da Figura 2 pode-se analisar que os grupos que estabelecem sede em Castanhal (Marilar e Jomóveis) realizam uma atuação mais abrangente e com um maior número de lojas, expandindo até para a área de atuação direta de Belém, ultrapassando os limites da região Nordeste do Pará. Este fato reflete as vantagens da centralidade de Castanhal sobre as outras duas cidades, Capanema e Bragança, por ter maior destaque dentro da rede e por possuir um centro comercial mais forte.

Capanema também possui importância, onde duas redes estabelecem sedes: Radisco, que tem uma forma de expansão mais voltada para o nordeste do Pará; e Eletromóveis, que atua apenas em cidades polos, com maiores áreas de

Estudos Geográficos, Rio Claro, 17(1): 159-174, jan./jun. 2019 (ISSN 1678-698X) http://www.periodicos.rc.biblioteca.unesp.br/index.php/estgeo 
influência, dinâmicas que podem ser percebidas na Figura 2. Esta cidade tem uma centralidade relevante para sua área de influência e um forte setor de serviço/comércio, mas com menos destaque comparada a Castanhal. Bragança, apesar de ter sido local de fundação da rede Jomóveis, não possui sede de nenhum grupo, isso reflete a perda de centralidade com relação às outras duas cidades, já que Bragança é a cidade mais antiga e possuía grande importância durante o funcionamento da EFB, mas com a remoção desta foi perdendo destaque no setor econômico, influenciando apenas três cidades e tendo arrecadação do PIB menor que Castanhal e Capanema.

Um fator importante que norteia a atuação dessas redes varejistas é o reforço para a sociedade, pois além de contribuírem na geração de empregos, melhorando o contingente de mão de obra assalariada dentro das cidades, a presença dessas redes possibilita a disponibilidade dos produtos para a população, desta forma, regulando o preço no mercado, já que o fator concorrência é um motivo significativo para incentivar as lojas a pensarem estratégias e outros fatores que atraiam clientes. Portanto, como esses grupos (Marilar, Jomóveis, Radisco e Eletromóveis) não possuem relações com outras redes de varejo, acabam tendo que se adequar a concorrência e desenvolver estratégias para se destacar perante a presença de grupos vindos da capital, e segundo as entrevistas realizadas suas logísticas de atuação tem dado certo.

Essas empresas, formadas a partir de grupos familiares e originárias do Nordeste Paraense se fortaleceram a partir da sua forma de gestão, que planeja suas articulações de espacialização e formas de atuação. A partir disso, cada rede varejista tem sua própria estratégia de localização, onde estabelecem critérios para a escolha de onde se fixar, de forma geral procuram sempre localidades polos e fazem análises de várias informações sobre as cidades.

Ainda assim, suas lógicas de funcionamento são distintas, como por exemplo a Radisco que só tem a intenção de atuar no nordeste do Pará, ou a Eletromóveis que já não expressa o interesse de expandir a rede, entretanto, busca melhorar sua estrutura funcional. Porém, todas essas redes utilizam de estratégias espaciais na sua atuação, pois localização é um fator de extrema importância para o sucesso no desenvolvimento de qualquer grupo varejista, e nesta dinâmica de funcionamento esses agente acabam ajudando a modelar o espaço urbano e fortalecer a rede urbana do Nordeste Paraense a partir das interações que estabelecem.

Estudos Geográficos, Rio Claro, 17(1): 159-174, jan./jun. $2019 \quad$ (ISSN 1678-698X) http://www.periodicos.rc.biblioteca.unesp.br/index.php/estgeo 
A estruturação da rede urbana...

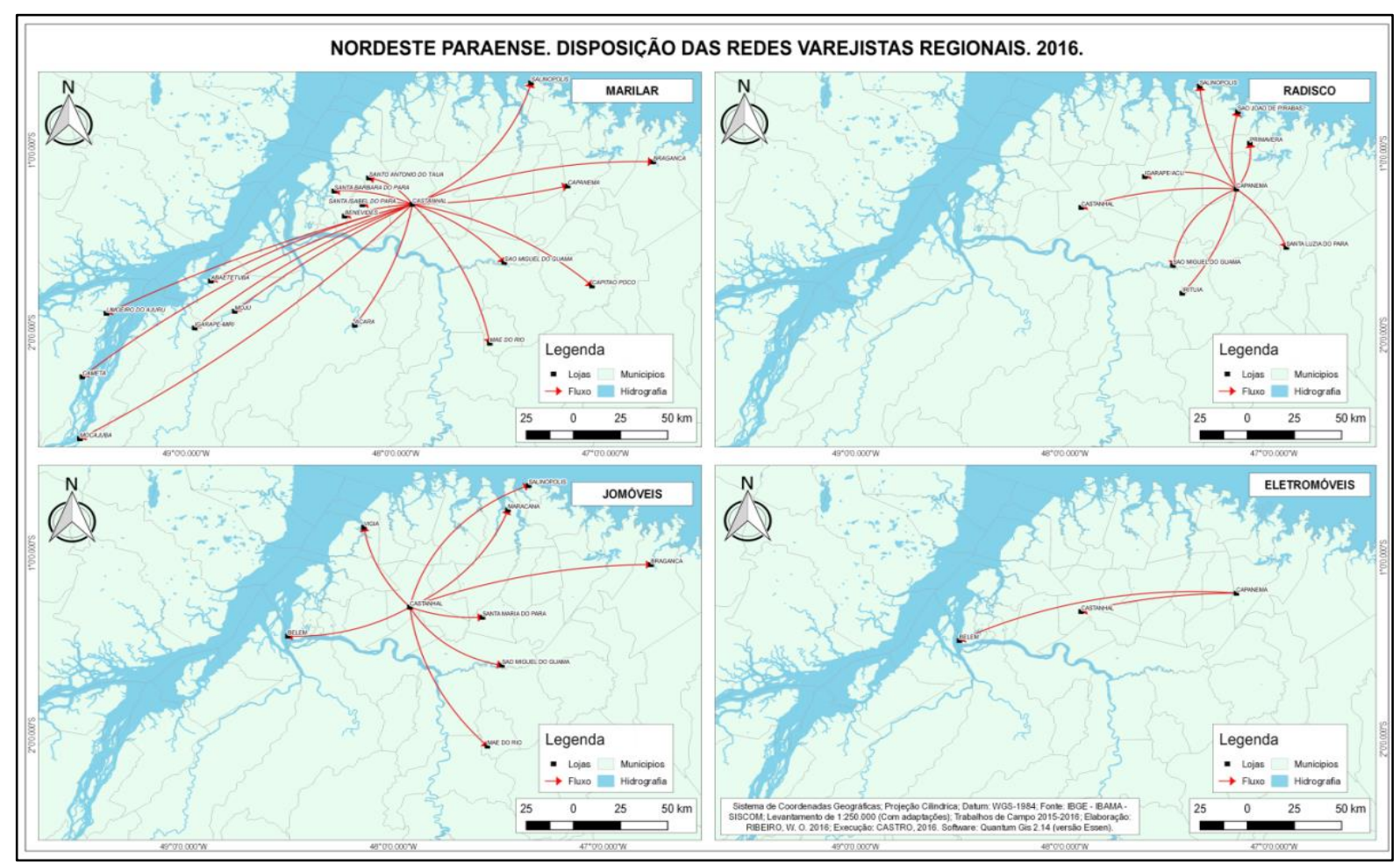

Figura 2 - Nordeste Paraense. Disposição das redes varejistas regionais: Marilar, Radisco, Jomóveis e Eletromóveis (2016).

Fonte: Ribeiro (2017).

Essa análise das formas de expansão das redes varejistas nos possibilita compreender a seguinte ideia: esses agentes tem uma contribuição mínima no processo de construção/formação dos centros urbanos nas cidades, já que eles procuram sempre atuar em centros já estabelecidos, entretanto, as redes tem um papel significativo no reforço das áreas comerciais das cidades, pois elas ajudam a fortalecer esses centros com sua presença e atuação, contribuem para a vinda de mais atividades/agentes, e favorecem o aumento da circulação nos centro.

Desta forma, partir da atuação das redes varejistas dentro dos centros urbanos, em especial os de Castanhal, Capanema e Bragança, ocorre uma valorização do comércio, já que a atividade varejista e o desenvolvimento das cidades estão intimamente ligados, como mostram Las Casas \& Barbosa (2007, p. 22):

A evolução histórica tanto do varejo brasileiro quanto o de outros países está diretamente relacionada ao cenário em que se assenta a infra-estrutura das cidades. Além disso, necessitam principalmente de uma concentração mercadológica que pressupõe a existência de pessoas, dinheiro, autoridade para comprar e, evidentemente, disposição para comprar. Adicionalmente à facilidade de transporte e comunicações, é determinante para o crescimento varejista o próprio crescimento das cidades. Basta comparar o comércio varejista de algumas capitais mais populosas com o das cidades interioranas para constatar essa evolução.

As interações que essas redes realizam contribuem ao articular os espaços reforçando a hierarquia entre os centros, já que a loja sede que possui maior destaque está sempre presente em uma cidade polo, e as filiais espalhadas em

Estudos Geográficos, Rio Claro, 17(1): 159-174, jan./jun. 2019 (ISSN 1678-698X) http://www.periodicos.rc.biblioteca.unesp.br/index.php/estgeo 
forma de rede ajuda no destaque de outros centros também. Essa hierarquia deriva do nível de cada cidade, da sua estrutura, de seus serviços e atividades presentes que ocasionam o deslocamento, e da intensidade desses deslocamentos para essas áreas.

Este fator de possibilidades que os centros oferecem para a implantação das atividades é o que se pode identificar nas cidades de Castanhal, Capanema e Bragança como uma herança da antiga EFB, pois seus desenvolvimentos foram alavancados pela implantação desta construção, e quando esta foi substituída pelas rodovias seus centros já eram polos, com presença de órgãos públicos e serviços de agentes privados, condições propícias para a atração e implantação de novas atividades econômicas, como a atuação das redes varejistas, que são favorecidas pela rede de circulação.

Desta forma, esses grupos contribuem para o desenvolvimento dos centros urbanos das cidades no sentido de fortalecer seu comércio (junto com outros serviços e agentes), e estruturar a centralidade, pois a partir da presença dos fixos (serviços e atividades) ocorrem os fluxos (deslocamento de pessoas). Neste sentido, é possível verificar a influência das redes varejistas tanto para o fortalecimento dos centros urbanos (principalmente os de Castanhal, Capanema e Bragança) como da rede urbana do Nordeste Paraense, pois a presença desses grupos ocasiona um impulso no deslocamento de pessoas que procuram seus serviços, que provavelmente não são disponíveis nos seus centros urbanos; essa atração para as cidades fortalece a estrutura do centro comercial, e junto com a presença de outros serviços, contribuem no destaque das cidades e contribuem para a sua hierarquia dentro da rede urbana do Nordeste Paraense.

Desta forma, a atuação de agentes como os grupos varejistas fazem parte da organização espacial dos centros urbanos, e como se espacializam em forma de rede estabelecem interações físicas (ex: movimentação de estoque) e imateriais (ex.: controle de informações e movimentação de capital), que conectam os centros urbanos, principalmente os de Castanhal, Capanema e Bragança, e também influenciam na atração populacional para essas cidades, que exercem centralidade, destaque dentro da região, e compõem a rede urbana do Nordeste Paraense.

As estratégias de atuação dos grupos varejistas fortalecem o setor econômico dos centros, a articulação em forma de rede que se comunica e interage a partir da sede, das filiais e dos centros de distribuição também ajudam a estruturar a rede urbana do Nordeste Paraense a partir dos polos urbanos articulados, como os de Castanhal, Capanema e Bragança, que exercem uma centralidade polarizando cidades menores, que recorrem a essas áreas centrais em busca de atividades e serviços diferenciados.

Essas cidades, como já foi destacado, possuem uma importância dentro da região do Nordeste Paraense polarizando sua área de influência, o setor de comércio/serviços é o de grande destaque destas cidades, essas são centros gestores e articulados, e as redes varejistas são agentes que realizam essa articulação, é por isso que Corrêa (1989) afirmar que "a rede urbana é um reflexo, em realidade, dos efeitos acumulados da prática de diferentes agentes sociais" ( $p$. 50), portanto se faz necessário analisar e compreender as ações e implantações das suas atividades, desvendar as intenções e identificar suas formas de articulação. É neste sentido que a atividade das redes de varejo compõe a interação espacial dos centros urbanos, reforçando suas centralidades e estruturando a rede urbana do Nordeste Paraense, através de operações e transferência dentro da cadeia de lojas.

Estudos Geográficos, Rio Claro, 17(1): 159-174, jan./jun. $2019 \quad$ (ISSN 1678-698X) http://www.periodicos.rc.biblioteca.unesp.br/index.php/estgeo 


\section{CONSIDERAÇÕES FINAIS}

Nas discussões feitas neste trabalho, ficou clara a compreensão do que seria a rede urbana a partir das proposições de Corrêa (1989, 2006b), enquanto um conjunto de centros funcionalmente articulados que se constitui a partir da estrutura territorial em que se expressa, resultante das ações dos diversos agentes.

A diversidade nas redes caracteriza suas regiões, pois as interações espaciais que as estruturam são produtos dos agentes locais de cada área, suas ações devem ser investigadas e analisadas para compreensão do espaço em rede. E para existir esse sistema complexo de relação e interações deve haver no mínimo uma economia de mercado com uma produção negociada por outra que não é produzida no local, haver pontos fixos que possa realizar as relações de troca, consumo, etc., e ter uma mínima articulação entre esses núcleos (CỎRRÊA, 1989), ocorrendo ao menos essas três situações uma rede urbana já pode ser estruturada.

A interação espacial é o componente estrutural de uma rede urbana, pois é a partir da relação entre os centros urbanos efetivada por diferentes sujeitos e agentes, por diversos motivos, que compõem a estrutura da rede. O comércio varejista é um setor que, além de ser o destaque em muitos centros urbanos, possui agentes que realizam a interação entre os espaços, como é o caso das redes de varejo que se organizam de forma articulada materializando seus fluxos por diversas cidades.

As redes de varejo são importantes vetores de interações espaciais, circulam informações, deslocam mercadorias e reforçam a conexão entre a cidades, estruturando a centralidade de cada uma delas (RIBEIRO, 2017). Essas interações são resultantes principalmente da diferenciação entre os espaços, o que faz os grupos varejistas estabelece critérios na escolha do local para se instalar e realizar análise desses centros urbanos. A análise desse processo a partir das redes varejistas no Nordeste Paraense foi pouco explorado, principalmente pelo fato das redes não serem originárias na capital, e sim nas cidades do interior do Pará - a partir de grupos familiares - ganhando dimensão importante para a lógica de organização do espaço.

A partir dos grupos varejistas estudados conseguimos compreender essa lógica de atuação e a importância da sua presença para a estruturação da rede urbana. Suas formas de espacialização são baseadas em análises dos centros urbanos, em que se verificam diversos fatores: contingente populacional e seu poder aquisitivo, estrutura dos centros comerciais, dinâmica interna, etc.; os fluxos que as redes varejistas realizam (de materiais, informações, capitais) fortalecem a relação entre o urbano no Nordeste Paraense, pois conectam as cidades mantendo-as interligadas. A natureza das interações espaciais das redes varejistas é hierárquica, isto por conta da sua forma de organização, pois possuem uma sede em que concentram as decisões, estoques, e estabelecem controle sobre as filiais, numa lógica de funcionamento associada à sua forma em rede. Este fator reflete nos centros urbanos que se instalam, pois a sede delas se localizam sempre em um lugar central, respeitando a hierarquia da região.

A presença desses grupos nos centros das cidades estrutura a área comercial, pois compõem o setor de serviços e atividades, fortalecendo o fator centralidade, além de ajudar na economia contribuindo nos impostos e movimentando o setor financeiro. Essas dinâmicas são processos sociais que integram a estrutura capitalista e que, segundo a lógica das redes varejistas,

Estudos Geográficos, Rio Claro, 17(1): 159-174, jan./jun. 2019 (ISSN 1678-698X) http://www.periodicos.rc.biblioteca.unesp.br/index.php/estgeo 
compõem a estrutura de uma rede, no caso, a rede urbana do Nordeste Paraense, ainda pouco explorada nas pesquisas acadêmicas.

A análise das redes varejistas além da contribuição para os estudos da rede urbana também reforçam o entendimento sobre o espaço intra urbanos, já que fazem parte da articulação entre as cidades e reforçam a hierarquia dos centros. A sede das redes varejistas possui maior destaque e tende a se instalar em cidades polos, para facilitar a logística, mas uma cidade que possui uma filial também se destaque diante daquela que não possui, por conta do fortalecimento do centro comercial.

Uma caracterização das redes varejistas é possuir muitas lojas dispersas por várias cidades, de se especializar em formato de rede, e como o setor de comércio/serviços é o de maior destaque na região, elas possuem uma importância decisiva na estruturação da rede urbana, pois estão entre as principais empresas deste setor, arrecadando valores maiores do que a indústria e agropecuária. Outra particularidade dessas redes varejistas estudadas é uma forma de atuação mais tradicional, se adequando com a região, o que se expressa na questão do crediário praticado por todas essas redes, uma forma de relação menos moderna mas que se encaixa com o poder aquisitivo local, o que difere do funcionamento dentro da RMB onde utilizam prioritariamente o cartão de crédito.

Desta forma, as redes varejistas originárias no Nordeste Paraense se organizam de forma estratégica com lógicas de espacialização e critérios espaciais definidos segundo sua gestão, reforçam a centralidade das cidades compondo o setor de mais destaque, e confirmam a hierarquia dos centros urbanos dentro da rede urbana. Elas adequam seu funcionamento de crédito de acordo com a característica da região, que mantém relações mais simples preferindo utilizar o crediário das lojas. Todo esse dinamismo de interações espaciais e lógica de atuação estrutura a rede urbana do Nordeste Paraense.

\section{REFERÊNCIAS}

CORRÊA, Roberto Lobato. A rede urbana. São Paulo: Ática, 1989.

. Interações espaciais. In: CASTRO, Iná Elias de; GOMES, Paulo Cesar da Costa; CORRÊA, Roberto Lobato (Orgs.). Explorações geográficas. 2 ed. Rio de Janeiro: Bertrand Brasil, 2006a.

Estudos sobre a rede urbana. Rio de Janeiro: Bertrand Brasil, 2006b.

ÉGLER, Eugênia Gonçalves. A zona bragantina no estado do Pará. Revista Brasileira de Geografia, Julho-Setembro 1961.

IBGE - Instituto Brasileiro de Geografia e Estatística. Regiões de Influência das Cidades 2007. Rio de Janeiro: IBGE, 2008.

Divisão Urbano Regional. Rio de Janeiro: IBGE, 2013.

LAS CASAS, Alexandre Luzzi; BARBOSA, Valdemirson Alves. Marketing no varejo. In: LAS CASAS, A. L. \& GARCIA, T. M. Estratégias de Marketing para Varejo: Inovações e Diferenciações Estratégicas que Fazem a Diferença no Marketing de Varejo. São Paulo: Novatec, 2007.

Estudos Geográficos, Rio Claro, 17(1): 159-174, jan./jun. $2019 \quad$ (ISSN 1678-698X) http://www.periodicos.rc.biblioteca.unesp.br/index.php/estgeo 
PEREIRA, Mirlei Fachini Vicente; KAHIL, Samira Peduti. O território e as redes: considerações a partir das estratégias de grandes empresas. In: GERARDI, Lucia Helena de Oliveira; CARVALHO, Pompeu Figueiredo de (org.) Geografia: ações e reflexões. Rio Claro: Programa de Pós-Graduação em Geografia, IGCEUNESP/AGETEO, 2006. p. 213-226.

RIBEIRO, Willame de Oliveira. Entre a metrópole e a cidade média: a complexidade das interações espaciais e das dinâmicas de centralidade da cidade de Castanhal, no nordeste paraense. Geousp - Espaço e Tempo (Online), v. 20, n. 1, p. 115-129, mês. 2016. ISSN 2179-0892.

- Interações espaciais na rede urbana do Nordeste do Pará: particularidades regionais e diferença de Bragança, Capanema e Castanhal. Presidente Prudente: Programa de Pós-Graduação em Geografia/FCT/UNESP, 2017.

TAVARES, Maria Goretti da Costa. O município no Pará: a dinâmica territorial municipal do município de São João do Araguaia. Rio de Janeiro: Pós-graduação em Geografia/UFRJ, 1992.

ULLMAN, Edward Louis. Geography as Spatial Interaction. Seatle and London: University of Washington Press, 1980. 